by means of photographing the waves' profile. The author also towed a flat plank, 28 feet long, at a speed of 406 feet a minute. The speed of current recorded at distances of I foot, 7 feet, I 4 feet, 21 feet, and 28 feet from the leading end were respectively 16 per cent., 37 per cent., 45 per cent., 48 per cent., and 50 per cent. of the velocity of the plank. These proportions appear to be maintained at all speeds between 200 and 400 feet per minute. Having thus determined the maximum velocity of the frictional water, other experiments were made with this plank to show the manner in which the motion of the water in contact with the surface was gradually imparted to the layers of water lying underneath. This was done by means of tubes, the forward ends of the tubes being open, and their after ends connected to gauge glasses. The results of experiments at 200,300 , and 400 feet per minute would appear to show that the velocity decreases in a geometrical progression as the distance from the surface increases in arithmetical progressions. The retardation of velocity in the somewhat analogous conditions of orbital wave motion of the flow of rivers, and possibly of glaciers, appears to confirm the foregoing observations as regards the ratio of decrease in velocity of the frictional weight. $\mathrm{Mr}$. Calvert next went on to refer to the labours of Dr. Froude, and his report to the British Association for 1874. We regret that space does not allow us to accompany him in this most interesting investigation, and we must refer our readers to the Transactions, in which the whole matter will be published in full. In the discussion which followed, Dr. White, Mr. Froude, and others spoke, but no new facts were brought forward.

The next paper of interest was a contribution by Mr. A. J. Durston, Engineer-in-Chief of the Royal Navy, and dealt with the important matters which are comprised in the problem of leaky tubes. Our readers will be aware of the trouble that has arisen in the Navy from the leakage at tubeplates and tube-ends, where marine boilers have been driven to their maximum. The difficulty has been got over to a certain extent by the introduction of a peculiar form of ferrule. These ferrules are bent over at their ends and protect the joint of the tube and tube-plate from the fierce impact of flame. Naturally the ferrules themselves get burnt away, as there is an air space between them and the heated surface of the boiler by which the heat would be abstracted from the end. With malleable cast-iron, the destruction is not so rapid as one would imagine, for, we believe, although the fact was not stated at the meeting-that a spare set is all that is provided for a commis. sion, that is to say, two sets of ferrules, one in position and one spare will last for three years. The experiments upon which Mr. Durston's paper is founded were made in various ways, with parts of boilers constructed especially for the purpose. The temperatures were generally ascertained by means of plugs at fusible alloys let into the plates through which the heat was transmitted. An interesting series of experiments was also made as to the temperature of the products of combustion at different distances within the tubes of a boiler. This was done by means of a Le Chatelier pyrometer. And it may be said that the curve of temperatures obtained in this way agrees very closely with the curve of evaporation obtained by Mr. Wye Williams. We have not space to give the details of $\mathrm{Mr}$. Durston's many trials. One very striking thing was the extremely deleterious result of grease in the boiler, by preventing the proper transmission of heat.

Mr. Milton's paper followed. Its object was to show that when a cylindrical boiler of the return tube type is subjected to pressure the staying of the combustion chambers to the shell has an effect of distorting the shell, dragging it out of the cylindrical form, thus the flat surfaces of the combustion chambers tend to bulge inwards on themselves, and away from the shell. This sets up strains which are not equally distributed around the whole circumference of the shell. In order to overcome this, Mr. Milton proposes to stay the combustion cham bers with stays radiating from the centre of the shell and distributed all round, so that the stress will be equal on all parts. The author quoted experiments showing that the distortion due to the cause named is far . greater than is generally supposed by engineers, in one case amounting to as much as one-eighth of an inch on the diameter. This was at a pressure of 320 lbs. on a boiler 14 feet in diameter having three combustion chambers.

Herr Schlick's paper was of remarkable interest. He has devised an instrument by which a record is obtained, not only of the vertical but of the horizontal vibrations of steamers. Without the aid of illustration it would be impossible for us to describe this very ingenious apparatus. Vibration is an important factor in the design of modern steamers of high speed. Our readers will remember Mr. Yarrow's contributions on this subject, and the very valuable practical results he adduced from the experiments made on torpedo boats. In ocean steamers the question of vibration is now one of great moment. In one wellknown Atlantic liner the vibration at one time was a serious objection to the vessel, and the nodal points of vibration were well marked in the length of the vessel, so much so that cabins on these points were greatly preferred, and those who were fortunate enough to be in the confidence of the stewards were able to secure these cabins. It has been shown that the action of the screw itself had very little to do with this vibratory disarrangement, it being the synchronisation of the reciprocating parts of the engine with the natural vibration of the structure of the hull that produces the effect in the most aggravated form.

Mr. Hök's paper on curves of stability is a valuable contribution to the Transactions of the Institution. The author is himself engaged practically in work of the nature which he describes, being a draughtsman in a shipyard on the north-east coast. The Institution can hardly have too many papers from authors of Mr. Hök's position and attainments. We do not propose here to enter into a description of the geometrical principles upon which the author bases his formula, and must refer our readers to the Transactions of the Institution for details. The system claims to give no more than approximation, but it is applicable to all kinds of ships and has the great merit of being readily constructed.

The last evening of the meeting Mr. John Inglis gave some interesting particulars of experiments made with a view to test the desirability of running triple compound engines as two cylinder compounds when low power only is required. The system has been frequently advocated with a view to save coal, but $\mathrm{Mr}$. Inglis's results do not seem to bear out this claim. Two four-hours' trials were made, one with the engine working as an ordinary triple, and the other with the intermediate cylinder thrown out of use. Working triple, the I.H.P. was 810 working two cylinders, $35 \mathrm{I}$. In the former case the coal consumed per I.H.P. per hour was 147 pounds. With the intermediate cylinder out of use the coal was $2 \cdot 238$. The consumption of feed water corresponding was $15^{\circ} 25^{2}$ pounds, and $23 \cdot 18$ pounds per I.H.Y. per hour. Of course the comparison must not be taken as indicating degree of the superiority of the triple expansion engines over the ordinary compound, great as that superiority undoubtedly is.

A paper by Mr. Cole on the same subject follows, but the results obtained are not sufficiently conclusive to demand quotation.

The last paper at the meeting was the contribution by $\mathrm{Mr}$. Edwards. Its title sufficiently explains its scope, and it would be quite impossible for us to follow the author's explanation without the aid of the diagrams which he exhibited on the walls of the theatre.

The chief event of the meeting was reserved for the last. It was the presentation of an address to Lord Ravensworth, who for fourteen years has occupied the position of president to the Institution. He now retires, his successor being Lord Brassey. The address referred to the great services that Lord Ravensworth had rendered to the Institution, and the authors of it gave utterance to no conventional platitudes. Lord Ravensworth has worked hard for the Institution of Naval Architects, and has conducted its meetings without favour to any, so that the humblest member could get a hearing equally with the most distinguished. It is not always so in societies of this nature.

A summer meeting of the Institution will be held at Cardiff, a very cordial invitation having been received from the Welsh metropolis. The meeting promises to be of unusual success, judging by the programme which is set forth, and the arrangements made.

\section{THE ACTION OF GLACIERS ON THE LAND}

PROF. T. G. BONNEY, F.R.S., read a paper to the

last meeting of the Royal Geographical Society on the question, Do glaciers excavate? In view of the correspondence recently published in our columns the arguments adduced in support of the negative conclusions may be cited in some detail. 
The question of the glacial origin of lakes involves many separate considerations. While lakes undoubtedly abound in regions now or formerly subjected to glaciation, many of these are formed by the damming of valleys by moraine heaps, or by extensive landslips. The school of Sir A. Ramsay affirm that glaciers are powerful excavating agents, and that there is no other agent but ice competent to form a rock-basin. The last argument breaks down when one considers the number of depressions of all sizes gradually increasing from mere volcanic craters to those of the Jordan Valley and the Caspian Sea, in the formation of which ice could have had no part. The argument that Greenland alone holds the key to the phenomena of glaciation breaks down, for the Alps were once the seat of a vast icesheet, which over-rode all the minor inequalities of the surrounding country, and of which the existing glaciers are the shrunken remnant. Thus the Alpine valleys should serve to show the typical results of ice-action on the land. This is the sum of their evidence : toothed prominences have been broken or rubbed away, the rough places have been made smooth, the rugged hill has been reduced to rounded slopes of rock (like the backs of plunging dolphins). But the crag remains a crag, the buttress a buttress, and the hill a hill; the valley also does not alter its leading outlines, the $\mathrm{V}$. like section so characteristic of ordinary fluviatile erosion still remains; all that the ice has done has been to act like a gigantic rasp; it has modified, not revolutionised, it has moulded, not regenerated. No sooner do we come to study in detail the effects of the ancient glaciers in the upper valleys of the Alps than we are struck by their apparent inefficiency as erosive agents. Here, where the ice has lingered longest, just beneath the actual glacier we see that a cliff continues to exist. Again and again in a valley we may find that on the lee side of prominences crags still reniain, sometimes in sufficient frequency to be marked features in the scenery. The Haslithal is an excellent and representative example. The result of prolonged personal study of the Alps may be summed up in the words- "Valleys appear to be much older than the Ice Age, and to have been but little modified during the period of maximum extension of the glaciers."

The evidence as to the erosive power of glaciers is very slight. Dr. Wright showed that the great Muir Glacier in Alaska covers great stretches of undisturbed gravel in which upright tree-stems remain. Prof. Bonney proceeded to say :In the Alps about the year 1860 the glaciers began to dwindle. By 1870 considerable tracts of bare rock or debris were ex posed, which a dozen years before had been buried under the ice. On none of these have I seen any basin-like hollow or sign of excavation as distinguished from abrasion. The Unter Grindelwald Glacier in the last stage of its descent passes over three or four rocky terraces. The angles of these are not very seriously worn away, nor are hollows excavated at the base of the steps. The bed of the Argentic̀re Glacier (I made my way some little distance under the ice) was rather unequal, and was less uniformly abraded than I had expected. There were no signs whatever of the glacier being able to break off or root up blocks of the subjacent schistose rock : it seemed simply to wear away prominences. This also is true of other glaciers. Prior to 1860 , and again in $189 \mathrm{I}$, I saw glaciers which were advancing. They ploughed up the curf of a meadow for a foot or two in depth; they pushed moraine-stuff in front of them, showing some tendency to over-ricie it, and nothing more. In 1875 , at the foot both of the Glacier des Bois and of the Argentiere Glacier, was a stony plain. Both these proved to have been recently uncovered by the ice; in other words, the glacier had not been able to plough up a boulder-bed even at a place where, owing to the change of level, some erosive action not unreason ably might have been expected. But, further, on both these plains big blocks of protogine were lying which were striated on sides and top, thus showing that the ice had actually flowed over them, as if it were a stream of mud. Some of the difficulties in the way of believing in the scooping out of lake-basins have now to be considered.

First, in regard to their position : some of them, such as Constance, Geneva, Como, Maggiore, \&c., are comparatively near to the lower limits of the great ice sheets, and so would be covered for a relatively short time. All of them are many miles from the ends of the existing glaciers, yet we are asked to admit that a rock basin, in depth sometimes exceeding rooo feet and generally more than 500 , has been scooped out in a time much shorter than that which has proved insufficient for the obliteration of the original features of the upper valleys or for the deepening of their beds by more than a few yards at most-indeed, as a rule, the ice seems never to have been able to overtake the torrent.

The radiating arms of the Lakes of Lucerne, Lugano, and Como are insuperable difficulties in the way of accepting a glacial theory of the origin of these lakes, and the configuration of the Lake of Geneva and the other lakes in France recently minutely surveyed, lends no countenance to the theory of excavation.

One fact to which Prof. J. Geikie has called attention seems at first sight strongly to support Sir A. Ramsay's hypothesis, and is the only real addition, in my opinion, which has been made to the original reasons. It is that many of the Scottish lochs are true rock basins, and that similar basins frequently occur outside their mouths. This also often holds of the fjords in Norway, New Zealand, and elsewhere. Prof, Geikie points out that several of these basins occur just when the ice might be expected to obtain an increased scooping power. His map at first sight appears very convincing; but a study of the larger charts reveals many anomalies. Loch Linnhe, for example, from below the entry of Loch Leven, maintains a general depth of from 34 to 50 fathoms ; then, below Loch Corrie, a channel may be traced whic 1 varies in depth from 50 to 60 fathoms, after which, in the Lynn of Morven, we find it deepen to 70 fathoms, then to go fathoms; and at last, a little north-east of the line joining Barony Point with Lismore Point, it expands into a basin with a maximum depth of $\mathrm{I}$ Io fathoms. But outside, in the Sound of Mull (to the north-west) the depths become very irregular, varying from about 35 to 70 fathoms. Barony Point appears to be connected with Mull hy a submerged isthmus, generally less than 20 fathoms below the surface. But here, if the glacier were stopped by impinging on Mull, it onght in splitting to be pushing hard upon its bed. In all this region the irregularities of the bed are very perplexing, whatever hypothesis be adopted; but $\mathrm{I}$ will restrict myself to a single instance. Off the west coast of Scarba, under the lee of the "Islands of the Sea," and where the opening towards Colonsay makes it improbable that the ice can have forced into a narrower space, an elongated basin occurs in which the soundings-outside about 60 fathoms-deepen to $\mathrm{roo}$, and at one place to 137 fathoms. The sea-bed about Arran presents similar difficulties. In short, here, at Loch Etive, Loch Lomond, and in other places, all goes well only so long as we restrict ourselves to generalities and abstain from details.

The theory of the origin of rock-basins, which I brought forward full twenty years ago, is now supported by much additional evidence. It is that the lake beds are ordinary valleys of sub-aerial erosion, affected by differential earth-movements. This has been very strongly confirmed by the surveys of the old beaches of the great lakes of North America, the Iroquois beach being full 600 feet higher at the north-eastern part than it is at the western end of Lake Ontario.

To conclude, glaciers, when the paths which they have traversed are carefully studied, appear to have acted, as a rule, as agents of the abrasion rather than of erosion. Even in the former capacity they have generally failed to obliterate the more marked pre-existent features due to ordinary fluviatile and sub-aerial sculpture. In the latter capacity they seem to have been impotent, except under very special circumstances; thus, while we may venture to ascribe to glaciers certain shallow tarns and rock basins in situations exceptionally favourable, we cannot assign to their agency either the greater Alpine lakes or any other important lakes in regions which were overflowed by the ice only during the period when it attained to an abnormal development. In the discussion which followed the paper, Dr. Blanford, Sir Henry IIoworth, Mr. Freshfield, and Mr. Conway took part.

\section{FURTHER STUDIES ON HYDRAZINE.}

A FURTHER contribution to the chemistry of hydrazine, $\mathrm{N}_{2} \mathrm{H}_{4}$, is communicated by Prof. Curtius to the current number of the Berichte. The first portion of the memoir deals with the preparation and properties of substituted hydrazines containing the radicles of the organic acids. In the latter portion a number of inorganic salts containing hydrazine are described. When hydrazine hydrate is brought in contact with the amides, NO. I 222 , vor. 47 ] 